\title{
Immunological Factors Influencing Liver Graft Survival
}

\author{
Robert D. (iordon, M.D. John J. Fung, M. D., Ph.D)., \\ Shunzaburo luatsudi, M.D. Kenc J. Duyasesous, M.D. \\ and Thombas E. Starzl, M.D., Ph.D.
}

Uncil recently, lack of suflicient case numbers and lack of time to periorm prospective preoperative testing made it difficult to examine the importance of such immunological lactors as $\mathrm{ABO}$ blosed-group matching preformed antidonor cytotoxic antiloody, or III.A-antigen matching on graft outcome in liver transplantation. However, with the increased experience of the last several years it is now possible to begin to assess the signiticance of these lactors.

\section{ABO BLOOD GROUPS}

The $A B()$ iscoughlutumins were the first preturmed antilsody system to be intensively studied. The ABC bleod group substances expressed on red blexed cells are also found in othere tissues, including the kiderey and the liver, and these organs do bund naturally excurring anti-A or anti-B

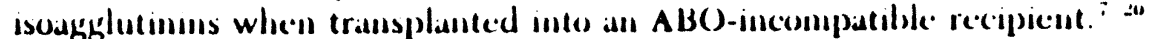

Transplantation of a kidney trom an $A B()$-incompatible donor results in hyperacute rejection of the allograft in most casces. Crossly, the organ turns dark and solt, usually within a kew minutes of revascularization in the recipient. Angiography of such kidneys demonstrates diffise closure of small vessels. Histopathologically, the arterioles and capillaries are clogged with blood elements, especially erythrocytes and platelets.

Alexandre and colleagues have demonstrated that $\mathrm{ABO}$ iscopghlutinins can be successtully removed by plasmapheresis and drug therapy to allow

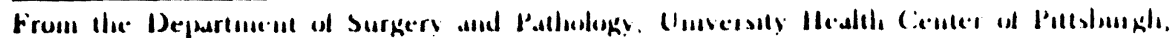

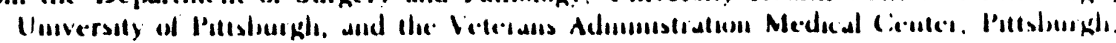
I'A

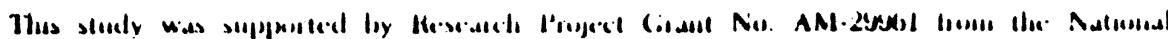

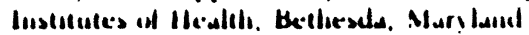


Graft Survival and ABO Matching

\section{x cratt surviva}

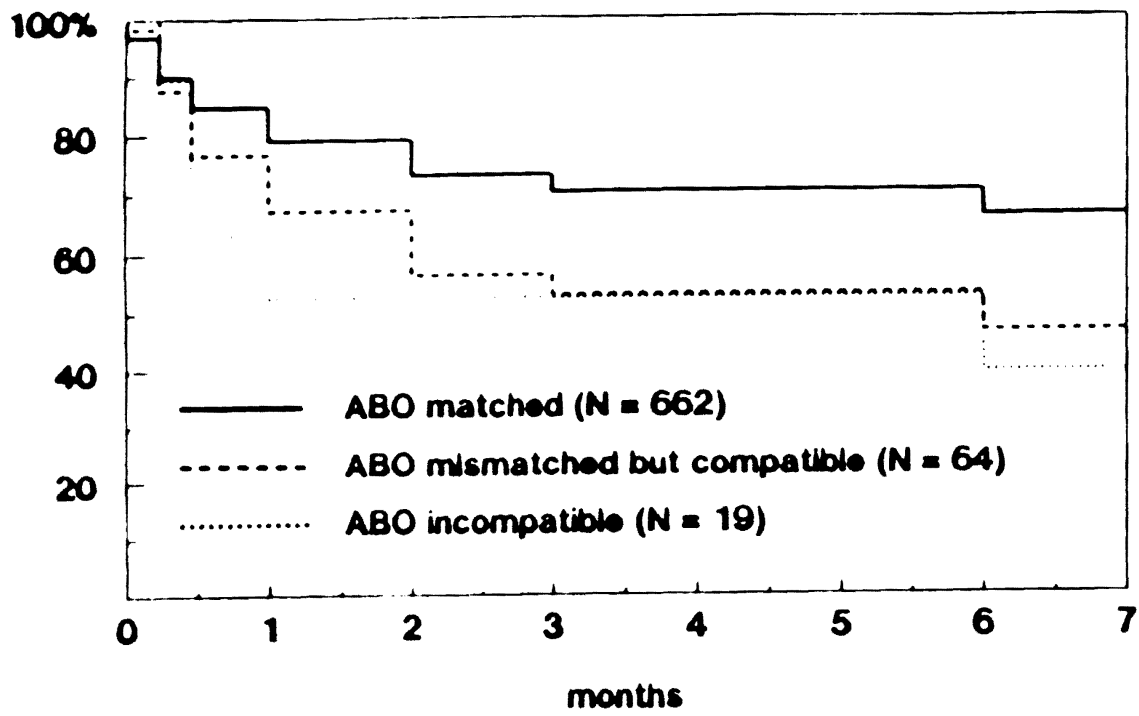

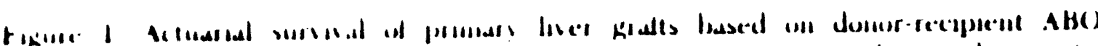

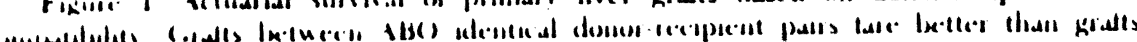

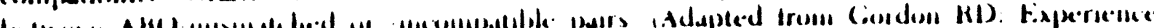
In In In

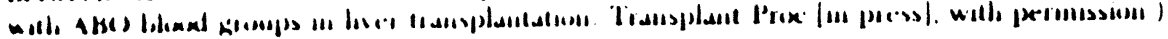

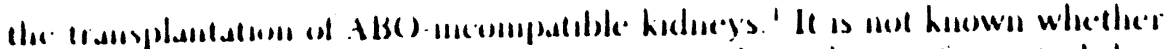

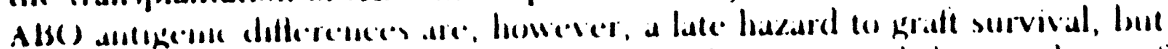

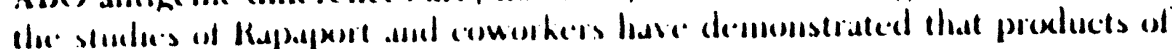

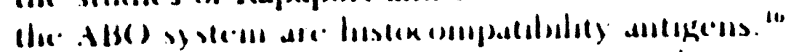

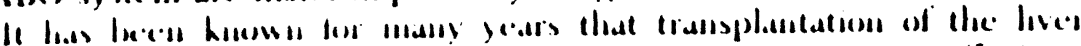

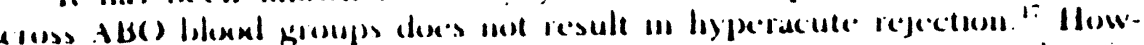

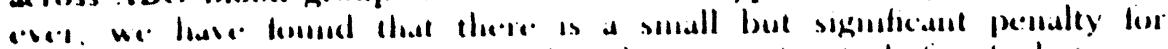

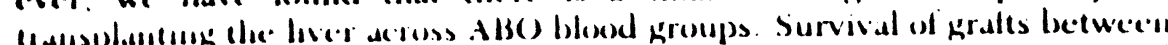

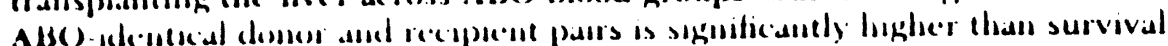
of AB( )-minsmatclied leat compatible or ABO-incompatible gratts. "

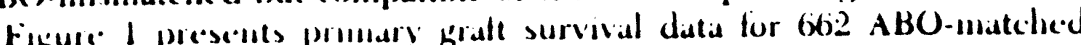

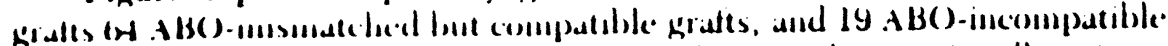

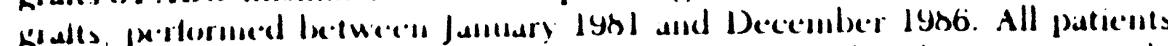

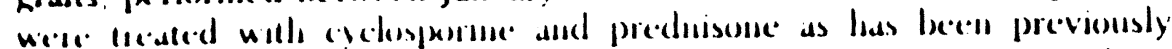

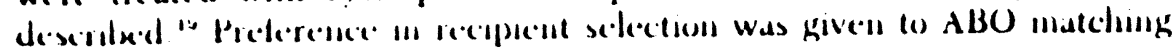

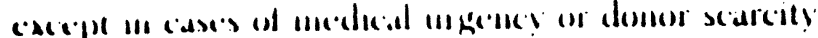

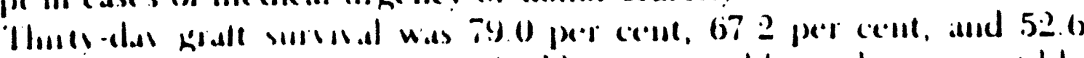

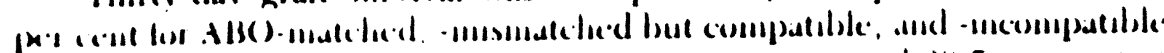

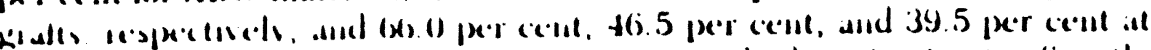

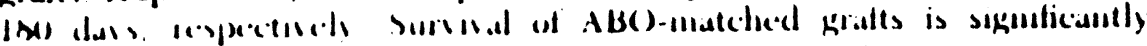

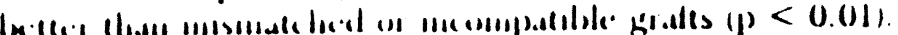

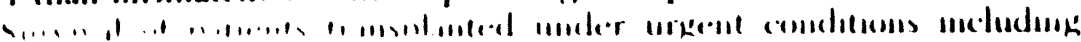

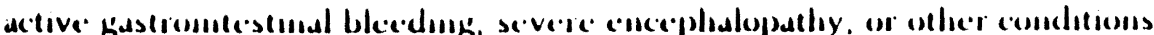

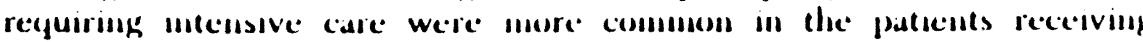
mismatched or incominatible gratts. However, when the data were adjusted by andyalyng only transplantiation of stable patients, there was still a significant survival advantage: for ABO-matched gralts $(p<0.05)$.

With AB()-mismatched livers, it is common for a graft-versus-host (CVH) reaction to develop 10 to 21 days after transplantation. ${ }^{13}$ In such cases, the productuon of anti-A of anti-B antibodies by donor $B$-lympliocytes transplanted with the gradt results in a hemolytic anemia. The heomolysis is usually self-liminted and mild, but III sume case's may be so severe that retransplantation is repuired. The: (iVII reaction complicaltes the manthagement of the patient and may, at least ill part, be respomsible for the poorer survival of AB()-mismatched grialts.

On the basis of these findings we limit use of $\mathrm{ABO}$-mismatched of incompatible gralts to urgent case's or lor cases where domor availability is severely lininted, such as for small children. Although there cleady is at significant risk in using such gratts, this risk illaty be less than the risks of sepsis, coagulopathy, central nervous system damagge, and metabolic derangentent associated with liver tallure.

\section{PKEFOKMED LYMPHOC:YTOTOXIC ANTIBODY}

Transplantation of the kidney to a recipsent with preformed circulating antibodies cytotoxic for donor lyinplioxyces is also assoxiated with a hyperacute rejection phenomenon." is. 22 A nentrophilic intiltrate and glomernalar

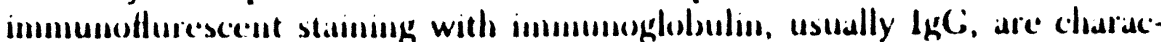
teristic findings on exalnination of such kidneys

Prior to transplantation, sermun fiom the potential recenpent is cross matched with lymphocytes from the denor to test for the presence of domos-

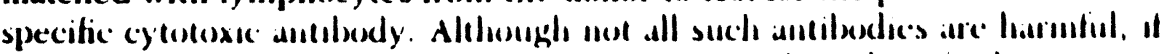
a positive test is obtentered, ancother recipsent is selected or further testing

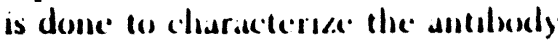

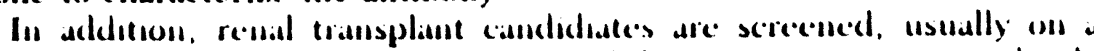

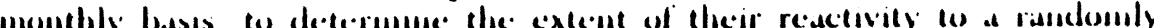

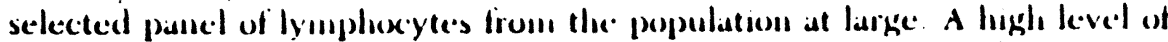
reactivity agrallust the pallel (percentagie pallel reactive antilsody or PKA) suggests a low probaluhlity of finding a crossmalch-negative donor. Furthermore, even if the donor-specific crossmatch is negative, thansplantation of a kidncy to a patient with a high PRA is associated with a decreadsed gradt survivial rate. ${ }^{1 .}$

In liver transplantation, the short cold storage times have not allowed routine prospective crossmatching in most cases, and therefore the: liver

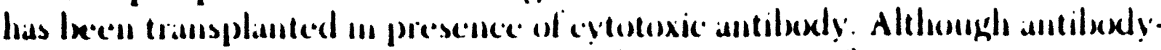

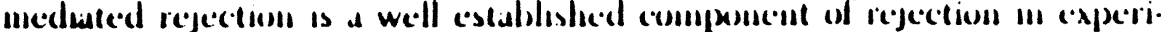

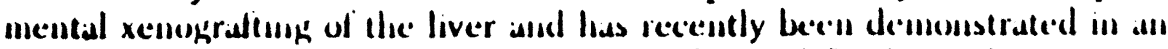

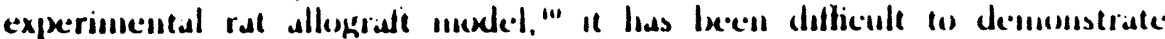
antibudy-incediated lisperacute rejections of the liver in the chisical setliing. 1: 
